\title{
Genome and proteome analysis of 7-7-1, a flagellotropic phage infecting Agrobacterium sp H13-3
}

Andrew M Kropinski ${ }^{1,2^{*}}$, An Van den Bossche ${ }^{3}$, Rob Lavigne ${ }^{3}$, Jean-Paul Noben ${ }^{4}$, Patrick Babinger ${ }^{5}$ and Rüdiger Schmitt ${ }^{6}$

\begin{abstract}
Background: The flagellotropic phage 7-7-1 infects motile cells of Agrobacterium sp H13-3 by attaching to and traveling along the rotating flagellar filament to the secondary receptor at the base, where it injects its DNA into the host cell. Here we describe the complete genomic sequence of 69,391 base pairs of this unusual bacteriophage.

Methods: The sequence of the 7-7-1 genome was determined by pyro(454)sequencing to a coverage of 378-fold. It was annotated using MyRAST and a variety of internet resources. The structural proteome was analyzed by SDS-PAGE coupled electrospray ionization-tandem mass spectrometry (MS/MS).

Results: Sequence annotation and a structural proteome analysis revealed 127 open reading frames, 84 of which are unique. In six cases 7-7-1 proteins showed sequence similarity to proteins from the virulent Burkholderia myovirus BcepB1A. Unique features of the 7-7-1 genome are the physical separation of the genes encoding the small (orf100) and large (orf112) subunits of the DNA packaging complex and the apparent lack of a holin-lysin cassette. Proteomic analysis revealed the presence of 24 structural proteins, five of which were identified as baseplate (orf7), putative tail fibre (orf102), portal (orf113), major capsid (orf115) and tail sheath (orf126) proteins. In the latter case, the $\mathrm{N}$-terminus was removed during capsid maturation, probably by a putative prohead protease (orf114).
\end{abstract}

Keywords: Agrobacterium, Phage evolution, Phage ecology, Genome, Proteome, Complex flagellum, Bioinformatics, Posttranslational modification

\section{Background}

Bacteriophage 7-7-1 is known to infect motile cells of Agrobacterium sp H13-3 (formerly Rhizobium lupini [1]), and as such is termed flagellotropic. Using electron microscopy, Lotz et al. [2] demonstrated translocation of phage 7-7-1 along flagellar filaments. Filament associated phage particles initially possess DNA-filled heads, which are subsequently found emptied when attached to the phage receptor at the flagellar base. This bimodal mechanism of adsorption dramatically increases the chance for finding the receptor at the cell surface, because (i)

\footnotetext{
* Correspondence: kropinsk@queensu.ca

'Laboratory for Foodborne Zoonoses, Public Health Agency of Canada, Guelph, ON NIG 3W4, Canada

2Department of Molecular \& Cellular Biology, University of Guelph, Guelph NIG 2W1, ON, Canada

Full list of author information is available at the end of the article
}

swimming bacteria with their flagella spread out act as a five- to 10-fold expanded target for the phage and, (ii) once attached, phage particles are directed to the receptor by a one-dimensional walk along the flagellum (instead of a random 'search' by three-dimensional diffusion). In no case has the process of phage translocation along the flagellum been visualized. Based on circumstantial evidence, Samuel et al. [3] have estimated that the flagellotropic phage $X$ of Salmonella needs $<1 \mathrm{~s}$ to reach the flagellar base. These authors have also provided evidence for a 'nut and bolt' mechanism by which phage $X$ moves along the filament. They argue that the long tail fiber fits the righthanded grooves between helical rows of flagellin subunits and that the counter-clockwise $(\mathrm{CCW})$ rotation of the flagellum forces the phage to follow the grooves as a nut follows the threads of a bolt.

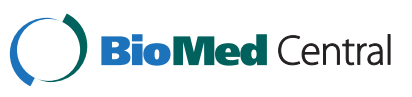


However, such conditions are not met by the 'complex' flagella of Agrobacterium sp H13-3. In fact, complex filaments exhibit a prominent pattern of right-handed helical ridges and grooves recommending itself as convenient 'threads', but the sense of flagellar rotation is exclusively clockwise (CW; [4-6]). Hence, 'nut and bolt' mechanics would force an attached phage particle to the distal end rather than to the flagellar base. Thus, the observed movement of 7-7-1 to the flagellar base demands a different, yet unknown mode of translocation. Differences between the two flagellotropic phages are also reflected by their distinct morphologies: electron micrographs of phage $X$ show a single long (200-220 nm) tail fiber wrapped around the 'plain' filament of Salmonella [7], whereas phage 7-7-1 exhibits five short $(16 \mathrm{~nm})$ tail fibers with splayed tips. Figure $1 \mathrm{~B}$ shows a scale diagram of phage 7-7-1 as deduced from high-resolution electron micrographs (Figure 1A).

7-7-1 is the first flagellotropic phage shown to infect a soil bacterium driven by the uni-directional $\mathrm{CW}$ rotation of its complex flagella, a pattern clearly different from the CCW-CW bias of the plain flagella driving Salmonella [9]. This departure from the well-studied enterobacterial paradigm and the rare phage morphology prompted us to analyze the genome and the structural proteome of 7-7-1.

\section{Results}

\section{Genome}

Electron micrographs of platinum/iridium-stained 7-7-1 DNA revealed mostly linear and a few circular molecules of approximately $25 \mu \mathrm{m}$ contour lengths (mass of $\cong 73.5 \mathrm{~kb}$; data not shown) suggesting DNA circularization by cohesive ends. These single-stranded termini are not covered by 454 sequencing. The 454 sequence data revealed that the genome of the phage was $69,391 \mathrm{bp}$ (52.4 $\mathrm{mol} \% \mathrm{G}+\mathrm{C})$. Following automated annotation using MyRAST the genome was manually curated revealing 127 ORFs and no tRNAs. The majority $(84,65.6 \%)$ of the ORFs showed no homology to any protein in the current NCBI databases. A minority showed similarity to
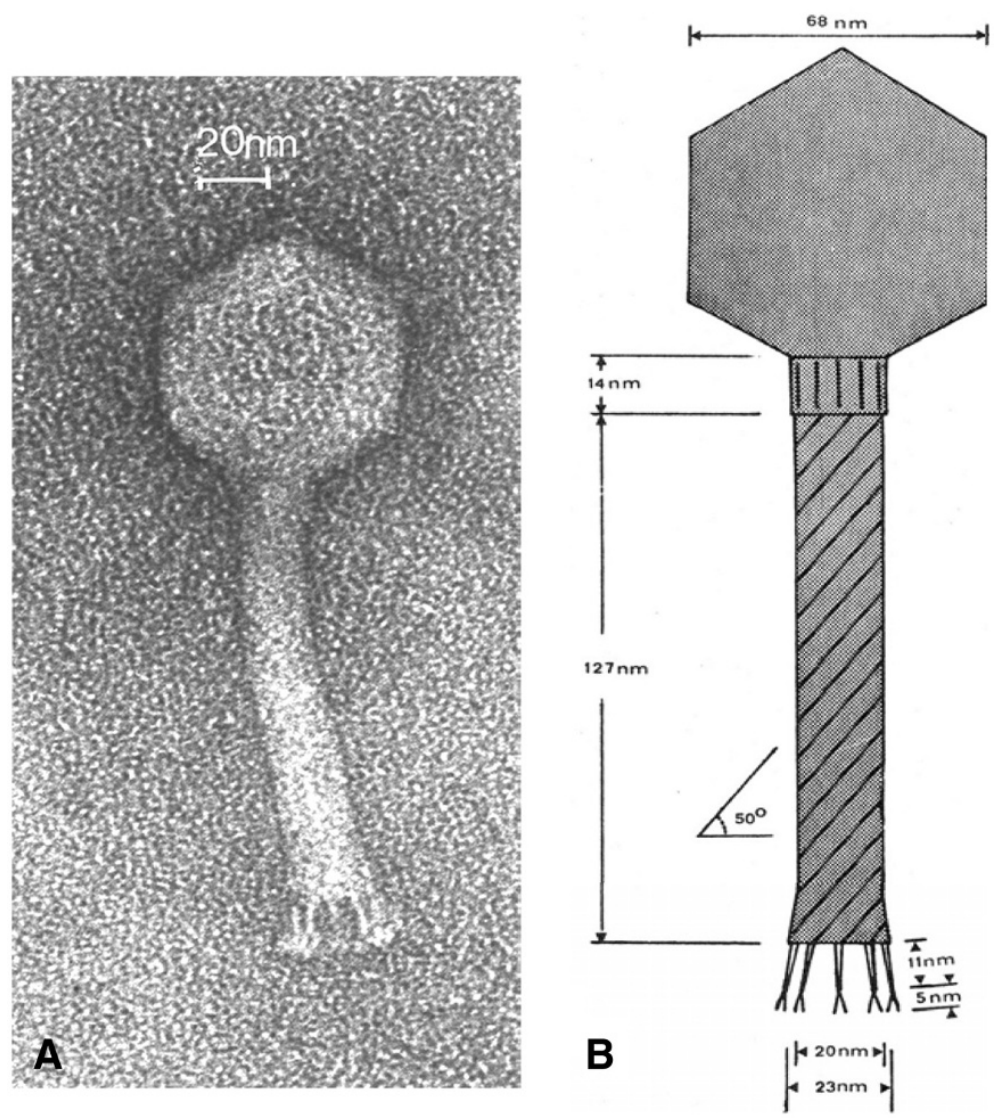

Figure 1 High-resolution electron micrograph (A) and scale diagram (B) of bacteriophage 7-7-1. A 14-nm collar connects the icosahedral head with the contractile tail that exhibits a surface structure of helical rows running at an angle of $50^{\circ}$. Five $16-\mathrm{nm}$ tail fibers with splayed tips probably lead the phage along the flagellar filament to the cell surface, where they act as specific adsorption organelles that attach the phage to its final receptor. Details of the tail fine structure were uncovered by optical diffraction [8] of highly resolved electron micrographs. 
prophage $(28,21.9 \%)$ or phage proteins $(16,12.5 \%)$. In the latter case 7-7-1 gp20-26 were collinear to a set of genes from Burkholderia phage BcepB1A [10] which is also a virulent myovirus. Phage 7-7-1 displays a number of unique features including the physical separation of the genes encoding the small (orf100) and large (orf112) subunits of the terminase complex. In addition, there is no evidence for a holin-lysin cassette (Figure 2; Additional file 1, Table S1).

\section{DNA replication}

DNA replication of this phage involves a helicase (orf23) and a polymerase (orf17). The latter shows greatest sequence similarity to the DNA polymerases of Pseudomonas phage 73 (YP_001293433) and Burkholderia phage BcepGomr (YP_001210246) which are members of the Siphoviridae, and Burkholderia phage BcepB1A (YP_024903) which, like 7-7-1, is a myovirus. An InterProScan shows it to be a member of the DNA/RNA polymerases superfamily (SUPERFAMILY SSF56672) with the motif located between residues 318 and 480. Two other proteins potentially involved in replication are the products of genes 28 and 33 . Gp28 is a 255 amino acid protein possessing ParB-like nuclease motifs (Pfam PF02195 ParBc; SMART SM00470 ParB-like nuclease domain and SUPERFAMILY [11] SSF110849 ParB/Sulfiredoxin) as well as ParB-like partition TIGRFAMs [12] protein motif TIGR00180 parB_part: ParB-like partition proteins. This type of protein has also been found in myoviruses such as Burkholderia ambifaria phage BcepF1 (YP_001039693), Mycobacterium phage Pio (AER49600) and enterobacterial phage P1 (AAQ14139). Gp33 contains a N-(deoxy)ribosyltransferase-like superfamily (SUPERFAMILY SSF52309) motif.

\section{Transcription}

Based upon the assumption that the genome circularizes via cohesive termini (not identified), there are two large transcriptional units encompassing orf 22-13 and orf 23-127, $1-12$. Since another member of the class $\alpha$-proteobacteria, Rhizobium etli, possesses rpoD-dependent promoters which closely resemble the Escherichia coli consensus sequence (TTGACA[N15-17]TATAAT) [13] we assumed that this phage might contain recognizable promoters. We identified five potential promoter sequences, including divergent promoters between the two transcription units (Additional file 2, Table S2). In addition four rho-independent terminators were identified and two high $\Delta G$ stem-loop structures. Interestingly, no bidirectional terminators were discovered between orf12 and orf13 (Additional file 2, Table S2). No evidence was found as to how transcription is temporally regulated in this virus.

The genome of phage 7-7-1 encodes for two proteins involved in DNA synthesis - a helicase (gp23) and a polymerase (gp17). The polymerase displayed no conserved motifs, and is distantly related to gp43 homologs from cyanomyoviruses. The helicase contained a high scoring (E-value: 1.01e-41) COG1061, DNA or RNA helicases of superfamily II protein motif (SSL2); and, homology to helicases from Burkholderia phage BcepB1A [10], and Vibrio phages VP16C and VT16T [14].

PSI-BLAST analysis of Gp3 against the NCBI virus database resulted in hits described as tail/DNA

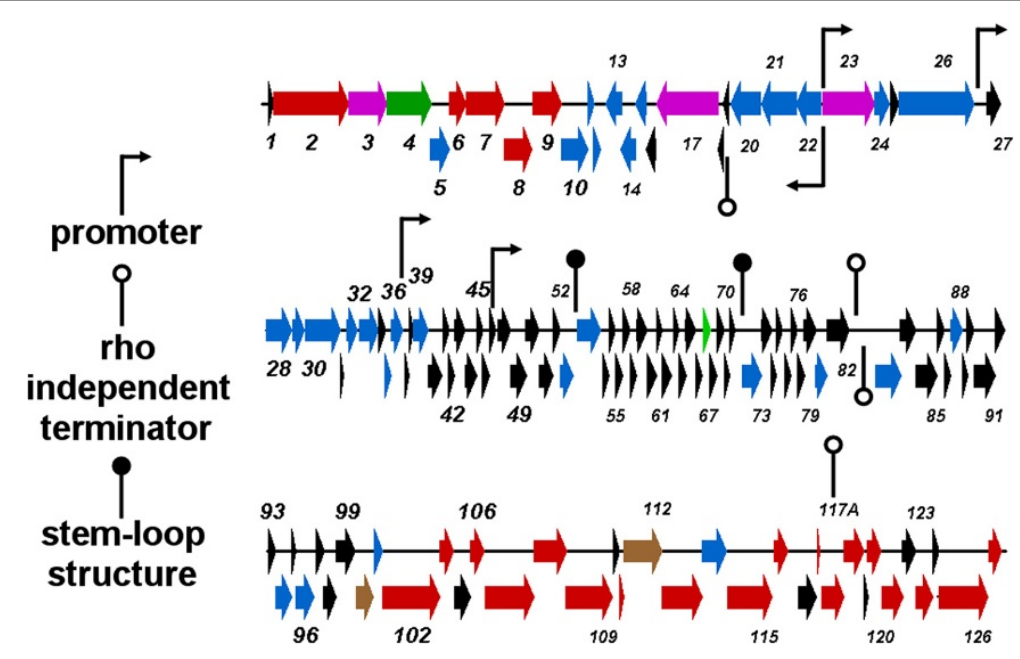

Figure 2 Genetic map of 7-7-1 showing genes encoding hypothetical proteins in black; conserved hypothetical proteins, blue; structural proteins, red; regulatory proteins, green; DNA and nucleotide metabolism, purple; terminase subunits, brown. Putative promoters are indicated with black arrows on stalks, while predicted rho-independent terminators are indicated with white circle on stalks, and stem-loop structures are indicated with black circle on stalks. 
circulation protein (Salmonella phage ST64B [15], Enterobacteria phage SfV [16], Pseudomonas phage DVM-2008, and Burkholderia phage KS10 [17]. This protein possesses two protein motifs: COG4228, Mu-like prophage DNA circulation protein, and pfam07157, DNA circulation protein N-terminus (DNA_circ_N) which are conserved protein domains of indeterminate function. Gp4 contains two inconsistent overlapping motifs: COG4379, Mu-like prophage tail protein gpP (Evalue: 2.99e-22), and, pfam05954, phage late control gene D protein (Phage_GPD; E-value: 1.76e-17). The homologs include tail proteins from $\mathrm{Mu}, \mathrm{D} 108, \mathrm{SfV}$ and ST64B. These results, coupled with the genome location and the observation that Gp3 is a structural protein (see next section), suggest that both of these proteins are involved in the sequence/assembly of the phage tail.

\section{Virion structural proteins}

BLAST analysis revealed several proteins as being involved in phage morphogenesis including baseplate protein (gp7), tail fibre (gp102), portal (gp113), prohead protease (gp114), major capsid (gp115) and tail sheath (gp126). HHpred $[18,19]$ analysis on other proteins in the morphogenesis cassette was used to identify three other proteins - gp5, gp6 and gp10. Gp10 which we had termed a conserved hypothetical membrane protein shows structural similarity (Probability $=91.01$; E-value $=0.11$ ) to RCSB Protein Data Bank [20] 3BKH, the lytic transglycosylase (gp144) of Pseudomonas phage $\varphi \mathrm{KZ}$ which is probably the endolysin for this virus [21]. Gp6 is related (Probability $=83.90$; $\mathrm{E}$-value $=0.63)$ to $2 \mathrm{IA} 7-$ a putative tail lysozyme (T4 gp5 analog); while gp5 is a structural analog of 3AJQ, phage P2 protein $\mathrm{V}$ which is the tailspike protein (Probability $=96.23$; E-value $=0.021)[22]$.

\section{Proteomics}

Electrospray ionization-MS/MS analysis of the structural phage proteins separated by SDS-PAGE led to the experimental identification of 24 virion proteins with sequence coverage from 8.4 to $85.7 \%$ (Table 1/Figure 3). Although only phage proteins with a minimum number of two unique peptides were considered, the identification of gp124 by a single peptide hit was approved based on a reliable proline spectrum [23]. Electrophoretic mobilities of the identified peptides were consistent with their predicted molecular masses, and seven of the nine visible protein bands on the gel could be unambiguously identified (Figure 3). Moreover, traces of the capsid (gp115) and the tail sheath protein (gp126) were identified throughout the gel, which can be explained by aspecific retention and partial degradation of these abundant proteins.

Although the major capsid protein gp115 is clearly the most abundant protein, only peptides of its C-terminus were found. This suggests that the $\mathrm{N}$-terminal part is cleaved off during maturation of the capsid. Indeed, similarity searches indicate that the C-terminal part of gp115 has high similarity with the major capsid protein of the HK97 family and that gp114 is similar to various prohead proteases. As the N-terminal part of the HK97 capsid is cleaved off by a prohead protease encoded by the upstream gene $[24,25]$, the protein band with a molecular weight of approximately $33 \mathrm{kDa}$ refers to the mature major capsid protein.

A final, remarkable finding is the identification of a small, 28 amino acid protein which originally fell below the threshold of gene prediction (i.e. $100 \mathrm{bp}$ ). Though the function of this polypeptide is unknown, the high 'protein identification probability' of $100 \%$ and the coverage of $85.7 \%$ confirmed its presence in the phage particle. This proves that proteogenomics, namely the use of proteome analysis to annotate the genome, is a powerful tool to identify missed protein-coding genes and thereby complements genome annotation.

\section{Discussion}

While a number of flagella-specific phages have been isolated - Salmonella phage $\chi$, Caulobacter phages $\varphi$ Cp34 [26], $\phi \mathrm{Cb} 13$ and $\phi \mathrm{CbK}$ [27], and $\varphi 6$ [28]; Bacillus phages AR9, 3NT, PBS1 [29], SP3 [30], and PBP1 [31]; Proteus phage PV22 [32]; Pseudomonas phage पCTX [33], Agrobacterium tumefaciens phages GS2 and GS6 [34]; Aeromonas hydrophila phage PM3 [35], and, Asticcacaulis biprosthecum $\varphi \mathrm{AcS} 2$, and $\varphi \mathrm{AcM} 4$ [36] - to the best of our knowledge only $\chi$ (Denyes, personal communication) and $\varphi$ CTX [37] have been sequenced. Using the BLASTP feature in BioEdit [38] the products of five 7-7-1 genes (13, 21, 26, 72 and 102) possessed homologs in Salmonella phage $\chi$. Interestingly, we defined gp102 as a putative tail fibre protein; and, it shows weak sequence similarity from residues $203-300$ to a similarly defined protein from phage $\chi$. In view of the quite different tail fibre morphologies observed in phage $\chi$ and phage 7-7-1, respectively, the region of similarity may define a general motif involved in phage-flagellum interaction.

Bacteriophage 7-7-1 shows relatively little overall DNA sequence similarity to other phages. At the protein level, CoreGenes revealed eight homologs of BcepB1A proteins, restricted to TerS and a variety of hypothetical proteins. These results indicate that phage 7-7-1 is unique and deserving of recommendation to ICTV as the type phage in a new genus: the 7-7-1-like bacteriophages.

\section{Materials and methods Bacteria and bacteriophages}

Agrobacterium sp H13-3 (formerly Rhizobium lupini H13-3) was isolated from the rhizosphere of Lupinus luteus [39]. 
Table 1 Overview of the structural proteins identified by ESI-MS/MS

\begin{tabular}{|c|c|c|c|c|c|c|}
\hline Protein number & Protein name & $\begin{array}{l}\text { Protein } \\
\text { MW (Da) }\end{array}$ & $\begin{array}{l}\text { Max. No. of } \\
\text { unique spectra }\end{array}$ & $\begin{array}{l}\text { Maxi. sequence } \\
\text { coverage (\%) }\end{array}$ & $\begin{array}{l}\text { Slice in which most } \\
\text { abundant }\end{array}$ & Remarks \\
\hline $\mathrm{gp} 2$ & $\begin{array}{l}\text { Conserved hypothetical } \\
\text { protein }\end{array}$ & 81,838 & 28 & $53.9 \%$ & 5 & \\
\hline gp3 & $\begin{array}{l}\text { Putative DNA circulation } \\
\text { protein }\end{array}$ & 43,673 & 6 & $22.6 \%$ & 9 & \\
\hline gp6 & $\begin{array}{l}\text { Conserved hypothetical } \\
\text { protein }\end{array}$ & 19,283 & 6 & $43.3 \%$ & 20 & \\
\hline gp7 & $\begin{array}{l}\text { Baseplate protein; phage } \\
\text { P2 GpJ homolog }\end{array}$ & 43,379 & 11 & $43.9 \%$ & 9 & \\
\hline gp8 & Hypothetical protein & 31,431 & 5 & $27.3 \%$ & 13 & \\
\hline gp9 & Hypothetical protein & 31,400 & 4 & $23.2 \%$ & $13-14$ & \\
\hline gp102 & Putative tail fibre & 61,504 & 6 & $17.7 \%$ & 4 & \\
\hline gp103 & Hypothetical protein & 14,237 & 4 & $44.7 \%$ & 22 & \\
\hline gp106 & Hypothetical protein & 14,221 & 7 & $51.7 \%$ & 23 & \\
\hline gp107 & Hypothetical protein & 52,046 & 18 & $36.9 \%$ & 1 & \\
\hline gp108 & Hypothetical protein & 37,504 & 3 & $13.5 \%$ & 11 & \\
\hline gp111 & Hypothetical protein & 4,295 & 2 & $45.2 \%$ & 25 & \\
\hline gp113 & Portal protein & 45,459 & 10 & $34.2 \%$ & 9 & \\
\hline gp114 & prohead protease & 28,590 & 2 & $10.5 \%$ & 18 & \\
\hline gp115 & Major capsid protein & 52,513 & 19 & $46.5 \%$ & $11-13-14$ & $\begin{array}{l}\text { only 'C-terminal' } \\
\text { sequence coverage }\end{array}$ \\
\hline gp116 & Hypothetical protein & 14,261 & 3 & $37.9 \%$ & $20-21-22$ & \\
\hline gp117A & Hypothetical protein & 3,205 & 4 & $85.7 \%$ & 25 & \\
\hline gp118 & Hypothetical protein & 24,820 & 9 & $44.3 \%$ & 14 & \\
\hline gp119 & Hypothetical protein & 22,041 & 9 & $84.7 \%$ & 17 & \\
\hline gp121 & Hypothetical protein & 15,986 & 3 & $35.0 \%$ & 19 & \\
\hline gp122 & Hypothetical protein & 23,047 & 6 & $20.5 \%$ & 15 & \\
\hline gp124 & Hypothetical protein & 20,253 & 1 & $8.4 \%$ & 18 & $\begin{array}{l}\text { protein identification } \\
\text { probability of } 87.70 \%\end{array}$ \\
\hline gp126 & Tail sheath protein & 54,066 & 21 & $50.5 \%$ & 7 & \\
\hline gp127 & Hypothetical protein & 14,475 & 5 & $50.7 \%$ & 18 & \\
\hline
\end{tabular}


(i)

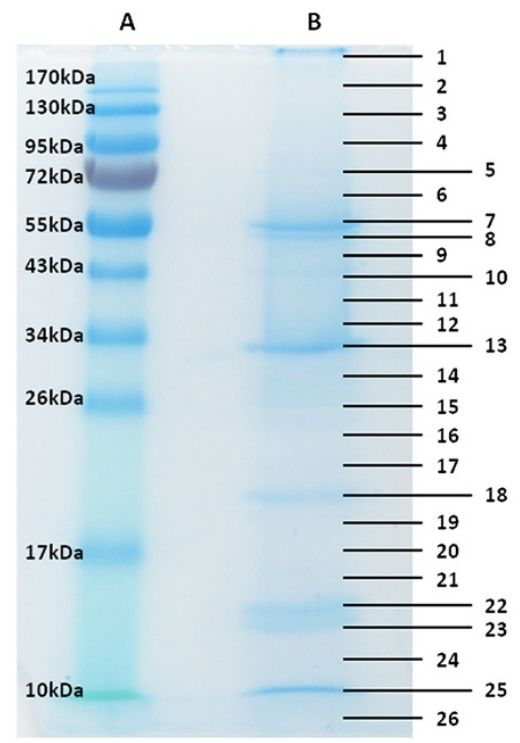

(ii)

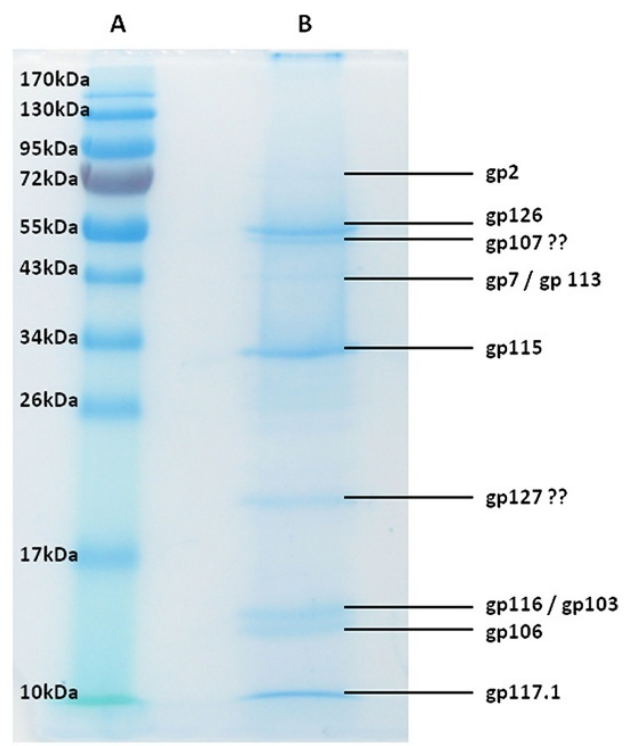

Figure 3 SDS-PAGE analysis of the purified structural phage proteins (lane B) on a 12\% SDS-PAGE separation gel alongside a PageRuler $^{\text {TM }}$ prestained protein ladder (Fermentas) (lane A). The entire lane was cut into numbered slices (i). Subsequently the origin of the visible protein bands were identified by ESI-MS/MS analysis (ii, showing Gps).

Phage 7-7-1, which is an isolate from garden compost [40], exclusively infects Agrobacterium sp H13-3 [1].

Bacteria were grown in NY medium (8 g nutrient broth, 3 g yeast extract per liter) at $40 \mathrm{rpm}$ in a gyratory shaker at $30^{\circ} \mathrm{C}$. Phage lysates up to $2 \times 10^{11} \mathrm{PFU}$ per $\mathrm{ml}$ were obtained by infection of an exponentially growing culture at $\mathrm{OD}_{650 \mathrm{~nm}}=0.1\left(8 \times 10^{7} \mathrm{CFU}\right.$ per ml $)$ with phage at an MOI of $5 \times 10^{-3}$ followed by threefold dilution with pre-warmed NY and further incubation pending lysis.

\section{Electron microscopy}

Purified phage particles were spread on carbon-coated copper grids, washed once with distilled water and then negatively stained with $4 \%$ uranyl acetate, $\mathrm{pH} 4.8$. Microscope magnifications were calibrated with a replica of an optical grating and micrographs were taken with a JEOL 7A (Japan Electron Optics Laboratory Co., Ltd.).

\section{DNA isolation for sequencing}

Phage DNA was isolated by phenol-chloroform extraction [41] and purified by using the Lambda DNA kit of Qiagen (Hilden, Germany). The DNA was subjected to pyrosequencing (454 technology) at the McGill University and Genome Québec Innovation Centre (Montreal, QC, Canada) to $378 \mathrm{X}$ coverage.

\section{Genome annotation}

The 7-7-1 sequence was initially subjected to automated annotation using MyRAST (http://blog.theseed.org/servers/ presentations/t1/running-a-job-with-the-desktop-rast.html), tRNAScan-SE [42] and ARAGORN [43], following which all open reading frames (ORFs) were confirmed using Kodon (Applied Maths Inc., Austin, TX. USA). The individual proteins were screened against the nonredundant protein databases in NCBI using Batch BLAST (http://greengene.uml.edu/programs/ NCBI_Blast.html). In addition they were screened for conserved motifs using InterProScan [44], Pfam [45], TMHMM v2.0 [46] and Phobius [47].

Putative promoters were identified based upon sequence similarity to the consensus RpoD-specific E.coli promoter sequence TTGACA[N15-17]TATAAT while rho-independent terminators were identified using ARNold [48,49] complemented with MFOLD [50].

The genome was submitted to NCBI and accorded accession number JQ312117.

\section{Comparative genomics}

This phage was compared at the DNA and protein levels to other related phages using progressiveMauve [51] and CoreGenes [52,53].

\section{Proteomics}

Structural phage proteins were purified as described by Moak and Molineux [54]. Briefly, a solution of CsClpurified phage particles $\left(10^{11} \mathrm{PFU}\right)$ was mixed with methanol and chloroform (1:1:0.75 by volume). After agitation and centrifugation, the upper layer was discarded and an equal volume of methanol was added. The protein pellet obtained by centrifugation at 14, $000 \mathrm{rpm}$ for $6 \mathrm{~min}$, was 
dried and resuspended in $12.5 \mathrm{mM} \mathrm{NH} \mathrm{NH}_{4} \mathrm{HCO}_{3}$. Subsequently, the heat denatured sample $\left(95^{\circ} \mathrm{C}, 5 \mathrm{~min}\right)$ was loaded on a $12 \%$ SDS-PAGE gel. The Coomassie-stained gel (Simply Blue Safestain; Invitrogen) was cut into slices, which were subjected to trypsin digestion [55]. Peptides were analyzed using electrospray ionization-tandem mass spectrometry (MS/MS) as described previously by Lavigne et al. [56]. The obtained spectra were screened against a database containing all 'stop-to-stop' protein sequences in all six frames. Generally, the identification parameters were a 'protein identification probability' of at least $99.8 \%$ and a 'best peptide identification probability' of $95 \%$.

\section{Additional files}

Additional file 1: Table S1. Characteristics of genes and proteins encoded by phage 7-7-1

Additional file 2: Table S2. Putative promoters and predicted terminators found in 7-7-1. Table S3. Mass spectroscopic analysis of individual gel bands, mzML formatted files in zipped format.

\section{Abbreviations}

BLAST: Basic Local Alignment Search Tool; ESI-MS/MS: electrospray ionization tandem mass spectrometry; Gp:: Gene product; HHpred: Homology detection \& structure prediction by HMM-HMM comparison; MOI:: Multiplicity of Infection, ratio of infective phage particles to vulnerable hosts; NY medium: Difco nutrient broth plus yeast extract; PFU:: Plaque Forming Unit, a measure of the number of viable viral particles; SDS-PAGE: denaturing (sodium dodecyl sulfate) polyacrylamide gel electrophoresis; TMHMM: TransMembrane prediction using Hidden Markov Models.

\section{Competing interests}

The authors have no competing interests to disclose.

\section{Authors' contributions}

AMK performed DNA sequence analyses and sequence annotation, $A V, R L$ and $\mathrm{JN}$ analyzed the proteome, PB and RS provided phage DNA, a high-titer lysate, and the fine structure analysis of 7-7-1 particles. All authors contributed to the writing of this manuscript. All authors read and approved the final manuscript.

\section{Acknowledgements}

We wish to thank Paul Thienel for artwork and Hermine Reisner for technical assistance. A.M.K. was supported by a Discovery Grant from the Natural Sciences and Engineering Research Council of Canada. AV holds a PhD scholarship of the FWO Vlaanderen.

\section{Author details \\ 'Laboratory for Foodborne Zoonoses, Public Health Agency of Canada, Guelph, ON NIG 3W4, Canada. ²Department of Molecular \& Cellular Biology, University of Guelph, Guelph NIG 2W1, ON, Canada. ${ }^{3}$ Division of Gene Technology, Katholieke Universiteit Leuven, Kasteelpark Arenberg 21, 3001, Heverlee, Belgium. ${ }^{4}$ Biomedical Research Institute and Transnational University Limburg, School of Life Sciences, Hasselt University, Diepenbeek, Belgium. ${ }^{5}$ Institut für Biophysik und physikalische Biochemie, Universität Regensburg, D-93040, Regensburg, Germany. ${ }^{6}$ Institut für Biochemie, Genetik und Mikrobiologie, Universität Regensburg, D-93040, Regensburg, Germany.}

Received: 3 January 2012 Accepted: 4 May 2012

Published: 31 May 2012

\section{References}

1. Wibberg D, Blom J, Jaenicke S, Kollin F, Rupp O, Scharf B, Schneiker-Bekel S, Sczcepanowski R, Goesmann A, Setubal JC, Schmitt R, Pühler A, Schlüter A: Complete genome sequencing of Agrobacterium sp. H13-3, the former
Rhizobium lupini $\mathrm{H} 13-3$, reveals a tripartite genome consisting of a circular and a linear chromosome and an accessory plasmid but lacking a tumor-inducing Ti-plasmid. J Biotechnol 2011, 155:50-62

2. Lotz W, Acker G, Schmitt R: Bacteriophage 7-7-1 adsorbs to the complex flagella of Rhizobium lupini H13-3. J Gen Virol 1977, 34:9-17.

3. Samuel AD, Pitta TP, Ryu WS, Danese PN, Leung EC, Berg HC: Flagellar determinants of bacterial sensitivity to chi-phage. Proc Natl Acad Sci USA 1999, 96:9863-9866.

4. Trachtenberg S, DeRosier DJ, Macnab RM: Three-dimensional structure of the complex flagellar filament of Rhizobium lupini and its relation to the structure of the plain filament. J Mol Biol 1987, 195:603-620.

5. Scharf B: Real-time imaging of fluorescent flagellar filaments of Rhizobium lupini $\mathrm{H13}$-3: flagellar rotation and $\mathrm{pH}$-induced polymorphic transitions. J Bacteriol 2002, 184:5979-5986.

6. Schmitt R, Bamberger I, Acker G, Mayer F: Feinstrukturanalyse der komplexen Geißeln von Rhizobium lupini H13-3. Arch Mikrobiol 1974, 100:145-162.

7. Schade SZ, Adler J, Ris H: How bacteriophage chi attacks motile bacteria. J Virol 1967, 1:591-598.

8. Yanagida M, Boy De La Tour E, Alff-Steinberger C, Kellenberger E: Studies on the morphopoiesis of the head of bacteriophage T-even. 8. Multilayered polyheads. J Mol Biol 1970, 50:35-58.

9. Schmitt R: Sinorhizobial chemotaxis: a departure from the enterobacterial paradigm. Microbiology 2002, 148:627-631.

10. Summer EJ, Gonzalez CF, Bomer M, Carlile T, Morrison W, Embry A, Kucherka AM, Lee J, Mebane L, Morrison WC, Mark L, King MD, LiPuma MJ, Vidaver AK, Young R: Divergence and mosaicism among virulent soil phages of the Burkholderia cepacia complex. J Bacteriol 2006, 188:255-268.

11. Wilson D, Pethica R, Zhou Y, Talbot C, Vogel C, Madera M, Chothia C, Gough J: SUPERFAMILY-sophisticated comparative genomics, data mining, visualization and phylogeny. Nucleic Acids Res 2009, 37:D380-D386.

12. Haft DH, Selengut JD, White $O$ : The TIGRFAMs database of protein families. Nucleic Acids Res 2003, 31:371-373.

13. Ramirez-Romero MA, Masulis I, Cevallos MA, Gonzalez V, Davila G: The Rhizobium etli sigma70 (SigA) factor recognizes a lax consensus promoter. Nucleic Acids Res 2006, 34:1470-1480.

14. Seguritan V, Feng IW, Rohwer F, Swift M, Segall AM: Genome sequences of two closely related Vibrio parahaemolyticus phages, VP16T and VP16C. J Bacteriol 2003, 185:6434-6447.

15. Mmolawa PT, Schmieger H, Heuzenroeder MW: Bacteriophage ST64B, a genetic mosaic of genes from diverse sources isolated from Salmonella enterica serovar typhimurium DT 64. J Bacteriol 2003, 185:6481-6485.

16. Allison GE, Angeles D, Tran-Dinh N, Verma NK: Complete genomic sequence of $\mathrm{SfV}$, a serotype-converting temperate bacteriophage of Shigella flexneri. J Bacteriol 2002, 184:1974-1987.

17. Goudie AD, Lynch KH, Seed KD, Stothard P, Shrivastava S, Wishart DS, Dennis JJ: Genomic sequence and activity of KS10, a transposable phage of the Burkholderia cepacia complex. BMC Genomics 2008, 9:615-615.

18. Hildebrand A, Remmert M, Biegert A, Soding J: Fast and accurate automatic structure prediction with HHpred. Proteins 2009, 77(Suppl 9):128-32. 128-132.

19. Soding J, Biegert A, Lupas AN: The HHpred interactive server for protein homology detection and structure prediction. Nucleic Acids Res 2005 33:W244-W248

20. Rose PW, Beran B, Bi C, Bluhm WF, Dimitropoulos D, Goodsell DS, Prlic A Quesada M, Quinn GB, Westbrook JD, Young J, Yukich B, Zardecki C, Berman HM, Bourne PE: The RCSB Protein Data Bank: redesigned web site and web services. Nucleic Acids Res 2011, 39:D392-D401.

21. Fokine A, Miroshnikov KA, Shneider MM, Mesyanzhinov W, Rossmann MG Structure of the bacteriophage $\varphi K Z$ lytic transglycosylase gp144. J Biol Chem 2008, 283:7242-7250.

22. Yamashita E, Nakagawa A, Takahashi J, Tsunoda K, Yamada S, Takeda S: The host-binding domain of the P2 phage tail spike reveals a trimeric iron-binding structure. Acta Crystallogr Sect F Struct Biol Cryst Commun 2011, 67:837-841.

23. Hunt DF, Yates JR III, Shabanowitz J, Winston S, Hauer CR: Protein sequencing by tandem mass spectrometry. Proc Natl Acad Sci U S A 1986, 83:6233-6237.

24. Duda RL, Martincic K, Hendrix RW: Genetic basis of bacteriophage HK97 prohead assembly. J Mol Biol 1995, 247:636-647. 
25. Huang RK, Khayat R, Lee KK, Gertsman I, Duda RL, Hendrix RW, Johnson JE: The Prohead-I structure of bacteriophage HK97: implications for scaffoldmediated control of particle assembly and maturation. J Mol Biol 2011 408:541-554.

26. Fukuda A, Miyakawa K, Iba H, Okada Y: A flagellotropic bacteriophage and flagella formation in Caulobacter. Virology 1976, 71:583-592.

27. Guerrero-Ferreira RC, Viollier PH, Ely B, Poindexter JS, Georgieva M, Jensen GJ, Wright ER: Alternative mechanism for bacteriophage adsorption to the motile bacterium Caulobacter crescentus. Proc Natl Acad Sci USA 2011, 108:9963-9968.

28. Jollick JD, Wright BL: A flagella specific bacteriophage for Caulobacter. J Gen Virol 1974, 22:197-205.

29. Vieira G, de Lencastre $H$, Archer L: Restriction analysis of PBS 1-related phages. Arch Virol 1989, 106:121-126.

30. Shea TB, Seaman E: SP3: a flagellotropic bacteriophage of Bacillus subtilis. J Gen Virol 1984, 65:2073-2076.

31. Lovett PS: PBPI: a flagella specific bacteriophage mediating transduction in Bacillus pumilus. Virology 1972, 47:743-752.

32. Zhilenkov EL, Popova VM, Popov DV, Zavalsky LY, Svetoch EA, Stern NJ, Seal BS: The ability of flagellum-specific Proteus vulgaris bacteriophage PV22 to interact with Campylobacter jejuni flagella in culture. Virol J 2006, 3:50.

33. Geiben-Lynn R, Sauber K, Lutz F: Flagellin inhibits Myoviridae phage $\varphi$ CTX infection of Pseudomonas aeruginosa strain GuA18: purification and mapping of binding site. Arch Microbiol 2001, 176:339-346.

34. Bradley DE, Douglas CJ, Peschon J: Flagella-specific bacteriophages of Agrobacterium tumefaciens: demonstration of virulence of nonmotile mutants. Can J Microbiol 1984, 30:676-681.

35. Merino S, Camprubi S, Tomas JM: Isolation and characterization of bacteriophage PM3 from Aeromonas hydrophila the bacterial receptor for which is the monopolar flagellum. FEMS Microbiol Lett 1990, 57:277-282

36. Pate JL, Petzold SJ, Umbreit TH: Two flagellotropic phages and one pilusspecific phage active against Asticcacaulis biprosthecum. Virology 1979, 94:24-37.

37. Nakayama K, Kanaya S, Ohnishi M, Terawaki Y, Hayashi T: The complete nucleotide sequence of $\varphi C T X$, a cytotoxin-converting phage of Pseudomonas aeruginosa: implications for phage evolution and horizontal gene transfer via bacteriophages. Mol Microbiol 1999, 31:399-419

38. Tippmann HF: Analysis for free: comparing programs for sequence analysis. Brief Bioinform 2004, 5:82-87.

39. Gábor M: Transformation of streptomycin markers in rough strains of Rhizobium lupini. II. The relation between the derterminant of streptomycin dependence and those for streptomycin resistance and sensitiveness. Genetics 1965, 52:905-913.

40. Lotz W, Mayer F: Electron microscopical characterization of newly isolated Rhizobium lupini bacteriophages. Can J Microbiol 1972, 18:1271-1274

41. Sambrook J, Russell DW: Molecular Cloning: A Laboratory Manual. Third editionth edition. Cold Spring Harbor, New York: Cold Spring Harbor Press; 2001.

42. Lowe TM, Eddy SR: tRNAscan-SE: a program for improved detection of transfer RNA genes in genomic sequence. Nucleic Acids Res 1997, 25:955-964.

43. Laslett D, Canback B: ARAGORN, a program to detect tRNA genes and tmRNA genes in nucleotide sequences. Nucleic Acids Res 2004, 32:11-16.

44. Quevillon E, Silventoinen V, Pillai S, Harte N, Mulder N, Apweiler R, Lopez R: InterProScan: protein domains identifier. Nucleic Acids Res 2005, 33:W116-W120.

45. Finn RD, Mistry J, Tate J, Coggill P, Heger A, Pollington JE, Gavin OL, Gunasekaran P, Ceric G, Forslund K, Holm L, Sonnhammer EL, Eddy SR, Bateman A: The Pfam protein families database. Nucleic Acids Res 2010 38:D211-D222.

46. Sonnhammer EL, Von HG, Krogh A: A hidden Markov model for predicting transmembrane helices in protein sequences. Proc Int Conf Intell Syst Mol Biol 1998, 6:175-182

47. Kall L, Krogh A, Sonnhammer EL: A combined transmembrane topology and signal peptide prediction method. J Mol Biol 2004, 338:1027-1036.

48. Gautheret D, Lambert A: Direct RNA motif definition and identification from multiple sequence alignments using secondary structure profiles. J Mol Biol 2001, 313:1003-1011.
49. Macke TJ, Ecker DJ, Gutell RR, Gautheret D, Case DA, Sampath R: RNAMotif an RNA secondary structure definition and search algorithm. Nucleic Acids Res 2001, 29:4724-4735.

50. Zuker M, Zuker M: Mfold web server for nucleic acid folding and hybridization prediction. Nucleic Acids Res 2003, 31:3406-3415.

51. Darling AE, Mau B, Perna NT: progressiveMauve: multiple genome alignment with gene gain, loss and rearrangement. PLOS One 2010, 5:e11147.

52. Kropinski AM, Borodovsky M, Carver TJ, Cerdeno-Tarraga AM, Darling A, Lomsadze A, Mahadevan P, Stothard P, Seto D, Van DG, Wishart DS: In silico identification of genes in bacteriophage DNA. Methods Mol Biol 2009, 502:57-89.

53. Zafar N, Mazumder R, Seto D: CoreGenes: a computational tool for identifying and cataloging "core" genes in a set of small genomes. BMC Bioinformatics 2002, 3:12

54. Moak M, Molineux IJ: Peptidoglycan hydrolytic activities associated with bacteriophage virions. Mol Microbiol 2004, 51:1169-1183.

55. Shevchenko A, Jensen ON, Podtelejnikov AV, Sagliocco F, Wilm M, Vorm O, Mortensen P, Shevchenko A, Boucherie H, Mann M: Linking genome and proteome by mass spectrometry: large-scale identification of yeast proteins from two dimensional gels. Proc Natl Acad Sci USA 1996, 93:14440-14445.

56. Lavigne R, Noben JP, Hertveldt $K$, Ceyssens PJ, Briers $Y$, Dumont $D$, Roucourt $B$, Krylov VN, Mesyanzhinov W, Robben J, Volckaert G: The structural proteome of Pseudomonas aeruginosa bacteriophage $\varphi$ KMV. Microbiology 2006, 152:529-534.

doi:10.1186/1743-422X-9-102

Cite this article as: Kropinski et al:: Genome and proteome analysis of 77-1, a flagellotropic phage infecting Agrobacterium sp H13-3. Virology Journal 2012 9:102.

\section{Submit your next manuscript to BioMed Central and take full advantage of:}

- Convenient online submission

- Thorough peer review

- No space constraints or color figure charges

- Immediate publication on acceptance

- Inclusion in PubMed, CAS, Scopus and Google Scholar

- Research which is freely available for redistribution

Submit your manuscript at www.biomedcentral.com/submit
C Biomed Central 